\title{
Congenital Hand and Foot Deformity
}

National Cancer Institute

\section{Source}

National Cancer Institute. Congenital Hand and Foot Deformity. NCI Thesaurus. Code C98896.

A malformation in the hand or foot that is present at birth. Representative examples include syndactyly, polydactyly, brachydactyly, and thumb hypoplasia. 